\title{
IMPROVED VIABILITY OF OFFSPRING WITH OESTROGEN SUPPLEMENTATION OF OVARIECTOMIZED RABBITS MAINTAINED ON PROGESTERONE
}

\author{
L. HEROD, JACQUELINE MORIER, J. LAWLESS AND J. T. LANMAN \\ Department of Pediatrics and Laboratory Animal Science Program, \\ Downstate Medical Center, Brooklyn, New York 11203, U.S.A.
}

(Received 12th August 1971, accepted 9th November 1971)

\begin{abstract}
Summary. Ovariectomized pregnant rabbits given sufficient progesterone maintained their pregnancies well but, after kindling, only a low percentage of young were found alive. Addition of oestradiol to the treatment regimen did not alter the effectiveness of progesterone in preventing abortion but increased the percentage of young found alive after parturition. The beneficial effect of oestrogen appeared to be related to a reduced incidence of prolonged pregnancies and prolonged labours, and suggested a rôle for oestrogen in the successful termination of pregnancy.
\end{abstract}

In the rabbit, the ovary is essential throughout gestation for the maintenance of pregnancy. In ovariectomized rabbits, pregnancy can be maintained by administration of progesterone and its withdrawal is followed by parturition. If, however, the objective is to simulate a normal pregnancy with the birth of viable offspring at full-term, the results so far obtained with progesterone replacement therapy appear to be poor, yielding few viable offspring. If such poor results could be confirmed, they might be shown to reflect a basic inadequacy of progesterone replacement therapy or merely an inappropriate dose level. It also seems possible that the addition of oestrogen to progesterone might influence the outcome of pregnancy, since oestrogen should also be deficient in the ovariectomized animal. In earlier studies (Courrier \& Kehl, 1938; Pincus \& Werthessen, 1938; Allen \& Heckel, 1939) of hormone replacement in ovariectomized rabbits, progesterone treatment has on occasion been supplemented with oestrogens, but usually only briefly, early in gestation, or only in one or two animals. More recently, Csapo (1969) has reported observations in pregnant rats ovariectomized $48 \mathrm{hr}$ before term. They found that none, or only a fraction of the litters of these animals were born, the remaining fetuses eventually dying in utero. Oestrogen substitution therapy, given as a single dose under various regimens, permitted the delivery of normal litters at term.

In our studies, trials were made in ovariectomized pregnant rabbits with progesterone in varying doses, with or without added oestrogen. The results 
confirmed that progesterone alone gave only a low percentage of living offspring despite the pregnancy being maintained. The addition of oestrogen to progesterone therapy resulted in a significantly higher percentage of living offspring being born but the effectiveness of progesterone in preventing abortion was not changed.

Thirty, sexually mature, female rabbits of mixed breeding and unknown parity, weighing 3 to $4 \mathrm{~kg}$, were mated and maintained in individual cages. Purina Rabbit Chow and water were given freely. The day of mating was counted as Day 0 . On Day 20, pregnancy was confirmed by palpation, and feed was withdrawn $24 \mathrm{hr}$ before surgery. Bilateral ovariectomies were performed on the 21st day of gestation under intravenous sodium pentobarbitone anaesthesia. Postoperatively, each doe was given Combiotic (Pfizer, 400,000 U penicillin-G and $0.5 \mathrm{~g}$ streptomycin) intramuscularly and assigned by random numbers to one of six treatment groups, each with five does. Progesterone (Schering) in sesame oil was administered intramuscularly daily to the various groups at three dose levels (Table 1), covering the range of inadequate to fully adequate dosage to maintain pregnancy in ovariectomized does, and at each dose level was tested with and without oestradiol dipropionate (Ciba) in sesame oil at an arbitrary dose of $1 \mu \mathrm{g}$ daily to determine whether added oestrogen altered the effectiveness of progesterone. Daily administration of oestrogen was chosen because the interval between ovariectomy and parturition, usually 10 to 14 days, afforded sufficient time for myometrial atrophy. Hormone therapy was begun on Day 21 and continued to Day 29, regardless of whether or when some or all of the fetuses were aborted.

All animals were inspected twice daily, at about 09.00 and 17.00 hours, to Day 35. If aborted fetuses were found, they were weighed and their condition (living or dead) recorded. The does were killed on Day 35, and their uteri were checked for retained placentae and fetuses.

The mean length of gestation in the various groups was a function of progesterone dosage and, for equal doses of progesterone, was not influenced by the addition of oestradiol to the hormone regimen (Table 1). However, the addition of oestrogen sharply increased the percentage of fetuses found alive after birth, from $20 \%$ to $73 \%$ in the groups receiving $2.5 \mathrm{mg}$ progesterone (Groups Ib and Ia, respectively), and from $18 \%$ to $56 \%$ in the groups receiving $1.5 \mathrm{mg}$ progesterone (Groups IIb and IIa, respectively).

Birth weights in the progesterone-treated groups $(\mathrm{Ib}+\mathrm{IIb})$ were compared with those of the oestrogen-plus-progesterone treated groups (Ia + IIa) for offspring born on Days 32 and 33; these were the only days when there were sufficient numbers of offspring to permit comparison. The mean weight ( \pm S.E.M.) in Groups Ia + IIa on Day 32 was $60.9 \pm 2 \cdot 3(\mathrm{~N}=35)$ and in Groups $\mathrm{Ib}+\mathrm{IIb}, 55 \cdot 3 \pm 4 \cdot 6(\mathrm{~N}=11 ; P=0 \cdot 25)$. The corresponding weights on Day 33 were $68.6 \pm 4.8(\mathrm{~N}=3)$ and $65.4 \pm 2 \cdot 3(\mathrm{~N}=10 ; P=0.82)$. Abortuses under $10 \mathrm{~g}$ (six in each of the combined groups) and two partially eaten dead fetuses were excluded from these calculations.

The results have confirmed that ovariectomized pregnant rabbits maintained on progesterone alone have only a low survival rate for spontaneously born offspring. The addition of oestradiol to the treatment regimen improved 
Oestrogen in ovariectomized pregnant rabbits

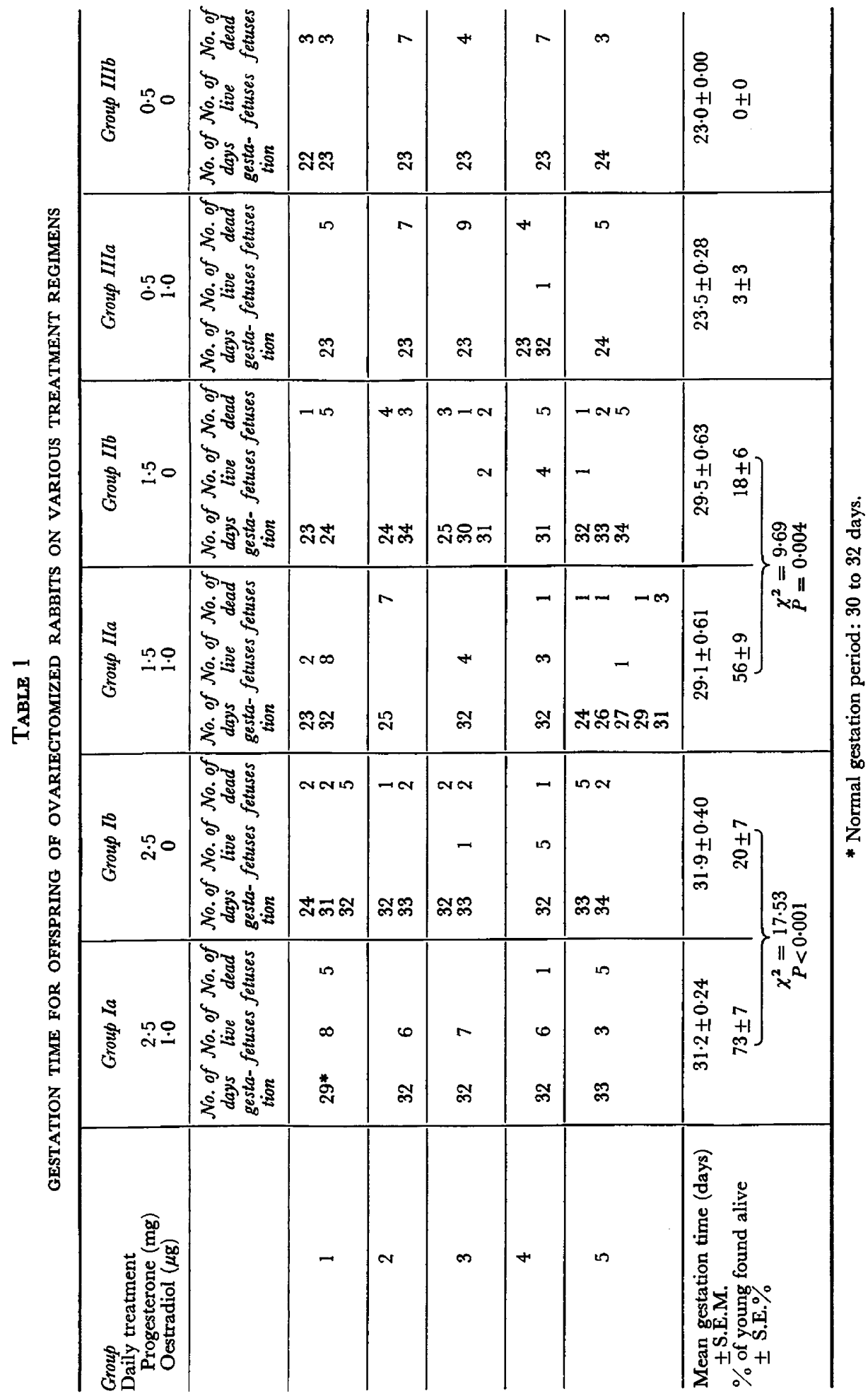


survival, and further examination of the data suggests that this was related to alterations in the character of parturition. The mortality (virtually $100 \%$ ) in both Groups IIIa and IIIb is clearly related to a dose of progesterone inadequate to maintain the pregnancy, and these two groups are excluded in the following analysis of comparative mortality. In the remaining groups, the higher incidence of offspring found dead after birth in the non-oestrogentreated animals as compared with the oestrogen-treated groups did not appear to reflect either poor fetal growth or the birth of a larger number of fetuses already dead for some time in utero, as shown by comparable fetal weights on Days 32 and 33 and by equal numbers of very small aborted fetuses. With comparable fetal weights and total number of offspring, it is likely that the total mass of the fetuses is also comparable, though amniotic fluid volumes were not measured. These volumes are normally very low at term in rabbits.

The high mortality rates in the non-oestrogen-treated groups (Ib and IIb) appeared to be related to prolonged gestation (delivery on Day 33 or later) and prolonged parturition (fetuses delivered over 2 or more days). One or both of these factors occurred in $80 \%$ of these ten pregnancies as compared with only $30 \%$ of the ten pregnancies in the oestradiol-treated groups (Ia and IIa). If pregnancies affected by either or both of these factors are excluded, survival rates are not significantly different in oestrogen and non-oestrogen-treated groups at corresponding progesterone dosage: $82 \pm 6.7 \%(\mathrm{~N}=33)$ and $83 \pm$ $15.3 \%(\mathrm{~N}=6)$ in Groups Ia and $\mathrm{Ib}$ and $53 \pm 12.9 \%(\mathrm{~N}=15)$ and $55 \pm 16.4 \%$ $(\mathrm{N}=9)$ in Groups IIa and IIb, respectively. These observations indicate that oestrogen supplementation improved the viability of offspring in these studies by influencing the time of onset and duration of parturition. The mortality associated with prolonged gestation might possibly have been avoided by earlier termination of progesterone treatment, but the mortality associated with prolonged parturition appears to reflect a rôle for oestrogen in normalizing the character of kindling.

This work was supported by a grant from the Association for Aid to Crippled Children, New York City. Progesterone was kindly supplied by the Schering Corporation, Bloomfield, New Jersey.

\section{REFERENCES}

Allen, W. M. \& Heckel, G. P. (1939) Maintenance of pregnancy by progesterone in rabbits castrated on the 11 th day. Am. 7. Physiol. 125, 31.

Courrier, R. \& KEHL, R. (1938) Sur le besoin hormonal quantitatif chez la lapine gestante castrée. C.R. Soc. Biol., Paris, 128, 188.

Csapo, A. (1969) The four direct regulatory factors of myometrial function. In: Progesterone: Its Regulatory Effect on the Myometrium, Ciba Fdn Study Grp No. 34, p. 13. Eds. G. E. W. Wolstenholme and J. Knight. Churchill, London.

Pincus, G. \& Werthessen, N. T. (1938) The maintenance of embryo life in ovariectomized rabbits. Am. F. Physiol. 124, 484. 